المجلة الأكاديية لمامعة نوروز

\title{
تحديات التدخل الخارجي على الدول العربية \\ التحديات الهثليمة انموذجاً
}

\author{
دمابراهيم علي كوو \\ مدرس \\ قسم العلاقات الدولية، كلية القانون والسياسة، جامعة نوروز \\ اقليم كوردستان - العراق
}

الملخص

التحديات الحتملة من النظام الوقلي في العقود الثلاثة الماضية من القرن العشرين والعقود القادمة هي تركيا ، وايران ، واسرائيل ، واثيوبيا وبعض الدول الافريقية وهذه التحديات متعددة ومتنوعة تواجه الدول

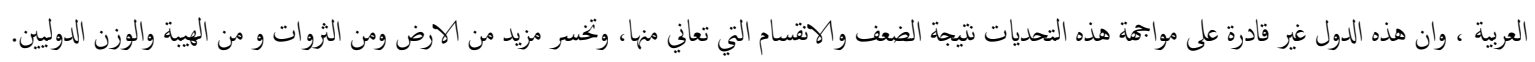

1

المنظومات الاقتصادية و السياسية القائمة تعرضت الى مزيد من التفكك والتشرذم والوهن، وان الدول العربية سوف تخسر المزيد من الارض وتشهد مزيد من التجزئة والاصطفاف مع الدول الاجنية الوقلمية والدولية وتزداد الصراع العربي - العربي و احتمال التجزئة في بعض اجزائه .

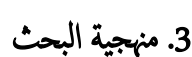

نظرا لطبيعة هذه التحديات وسعة دائرته وتعدده وجذوره العميقة منذ تأسيس الدول العربية بعد سايكس بيكو في العشرينات القرن العشرين اعتمد البحث على المنهج التاريخي لتوضيها، فضلا عن دراسته ضمن المنهج التحليلي و المنهج السياسي المقارن.

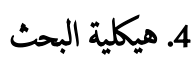

تم تقسيم هذا البحث الى ثلاثة مباحث رئيسة وخاثمة، عالج المبحث الاول غايات التدخل الخارجي ، وتطرق المبحث الثاني الى التحديات الوقليمة الاسيوية على الدول العربية ، وبدوره قسمنا هذا المبحث المى ثلاثة مطالب ، المطلب الاول - التحدي التركي ، والمطلب الثاني - التحدي الاسرائيلي ، والمطلب الثالث - التحدي الايراني. ثم تناول المبحث الثالث التحديات الوقليمة / الافريقية على الدول العربية ، وبدوره تم تقسيم هذا المبحث المى ثلاث مطالب، المطلب الاول - التحدي الاثيويي ، والمطلب الثاني - التحدي التشادي- اللبيي والمطلب الثالث التحدي السنغالي
لبيان ابرز التحديات التي تواجه الدول العربية في المشرق، وتشخيصها، ومعرفة درجة خطورتها وتهديدها على الوجود والقيم والاقتصاد والجغرافية.

2.1

نطرح اشكالية هذا البحث من خلال السؤال الرئيسي الاتي:• ماهي التحديات الوقليمة على الدول العربية ؟ ويتفرع منها الاسئلة الفرعية الاتية:O ماهي التحديات الوقليمة/ الاسيوية على الدول العربية في المشرق العربي؟ O ماهي التحديات الوقليمية / الافريقية على الدول العربية في المغرب العربي؟ O ما هي غايات التدخل الخارجي على الدول العربية؟ O هل هذه الغايات تهديد على الجغرافيا والاقتصاد والوجود والقيم والكيان؟

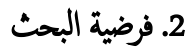
الدول العربية غير قادرة على موابجة هذه التحديات المتعددة والمتنوعة، لأهها تتعرض يوما بعد يوم المى مزيد من الانقسام والضعف والتفكك والاستقواء بالخارج، وحتى

\begin{tabular}{|c|}
\hline 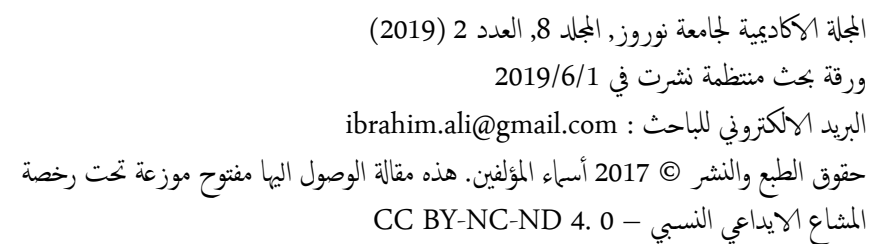 \\
\hline
\end{tabular}


ت- ومنذ ثلاثينات القرن العشرين دع الغرب الكولونيالي نشوء المالك والامارات 5 في شبه الجزيرة العربية وارسى معها تسوية تاريخية ، وارتكز حاية انظمتها مقابل تضمنت اهم النتائُ والتوصيات التي توصل اليها البحث.

ان تؤمن له مصالحه الاقتصادية والسياسية (2).

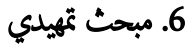

ث- استدعت خطة التدخل الخارجي ان ينفذ الغرب وعد بلفور عام 1917 1.6 غايات التدخل الخارجي على الدول العربية الصادر من دولة عظمى بحاية كلونيالية ، فكانت دولة اسئيل في فلسطين، التي شكلت الحاجز الدولي بين المشرق والمغرب العربيين ولعبت دور الاداة لتامين مصالحه الاستراتيجية وذلك بعد ان ضمن لها السيطرة العسكرية على

المنطقة (3).

لقد شهدت البلاد العربية بعد نكبة فلسطين موجة من التحولات السياسية والانقلابات العسكرية فنشات في ظلها انظمة وطنية وقومية مما نشات انظمة طائفية ومشيخية وكان ذلك يترافق مع تناي المد القوي في المخسينيات والستينيات في القرن الماضي ، ثم تغير المشهد في اعقاب معاهدة كامب ديفيد عام 1978 ، ودخل العالم العربي في الثانينات في حالة قصوى من الاضطراب السياسي الذي اتخذ مع مطلع التسعينات شكل الحرب الاهلية تارة ما الجزائر والحرب البينية العراق والكويت تارة اخرى ومع بداية الالفية الثالثةكان النظام العربي الرسمي يخسر رهانه على السلام وكانت بلاد الخليج تخضع للاستعار المباشر في نطاق عملية احتلال العراق ، والتدخل الخارجي يكيف خطنه الاصلية وفق اشكال تلأمكل مرحلة من مراحل التطور في الواقع العربي وبالشكل الاتي : - و

- انشا الغرب حلف بغداد في منتصف المخسينات القرن الماضي عام 1955 للرد على المناخ الوحدوي ولتطويق لحدود الجنوبية للاتحاد السوفيتي درءا للخطر الامر ، وقد وجد الارضية العربية ملائمة انخرط معه نظام قبلي هنا ونظام طائني

- عمل الغرب على ضرب الوحدة بين سوريا ومصر في عام 1961 .

كثفت هزيمة حزيران عام 1973 ان الندخل الغربي الى جانب اسرائيل لم يكن هدفه احتلال الارض ، بل كان مهدف الى ضرب المشروع النضوي التحديثي

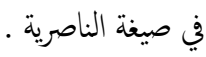

ابجاض اية محاولة تحديثية يجري بناؤها في البلاد العربية ، وقد دل هذا

على ان الغرب ينادي بتحديث اخر غير الغربي وفق نموذجه ويحول دون

$$
\text { تحديثه بشتى الوسائل في الوقت ذاته . }
$$

منع قيام اية وحدة بين بلدين عربيين او اكثر ذلك، لان الوحدة تهدد مصاح الغرب تنع اعادة رسم خريطة المنطقة وفقا لاجندتهم وتراعي مصالحهم .

هاستتباع اقتصادي وسياسي للكيانات العربية من اجل توفير افضل

الشروط لاستمرار سيطرة الغرب عليها (1).

ب- عع انهيار السلطنة اخذ الغرب الكولونيالي يطبق استراتيجيته في التدخل في ظروف جديدة ، فلم يتاخر في ان يرسم من خلال اتفاق سايكس بيكو عام 1916 وخريطة بلاد المشرق تلبية لمصالحه واطاعه ثخ تخلى عن دعه لمشروع الشريف حسين واندفع على ضربه في معركة ميسلون عام 1920 ، وجعله يندرج في خطة التجزئة وفق موازين القوى ، وهذه الخطة قامت على مرتكزات ذات

اولوية استراتيجية منها :-

رفض اي مشروع توحيدي واسقاطه بالقوة العسكرية ، اذ مثلما تخلت فرنسا عن محمد علي تخلت بريطانيا عن الشريف حسين ، فالاخلاص عند الغرب للخطة وليس للاصدقاء ، انها طبيعة وسلوك قد بناها الغرب منذ

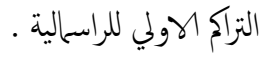
معاداة العروبة والاسلام او اية رابطة جامعة للبلاد العربية وتغذية الهويات الهقيمية والكيانات والمفردة التي تتساوق بشكل او باخر مع خريطة التجزئة . 


$$
\begin{aligned}
& \text { لذا سوف نحلل هذه التحديات من خلال ثلاث مطالب نتطرق: } \\
& \text { - في المطلب الاول: التحدي التركي } \\
& \text { - في المطلب الثاني: التحدي الاسرائيلي } \\
& \text { - - في المطلب الثالث: التحدي الايراني }
\end{aligned}
$$

1.1.7 المطلب الوول : التحدي التركي

انضمت تركيا المى حلف بغداد عام 1955 وكان هذ التحالف محل ترحيب زعاء الحزب

الديمقراطي التركي الذين تسلموا السلطة في ايار عام 1950 ثم عادوا لتعزيز مركزه في الانتخابات عام 1954 فقد اغرتهم رؤية تجمع يتمكن من ضمكل الدول العربية ان لم نقل الدول الاسلامية تحت القيادة التركة إذكانت تساورهم اوهام اعادة امجاد الامبراطورية

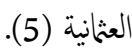

وفي الام المتحدة، عارضت تركيا منح الشعب الجزائري الاستقلال في ستينيات القرن العشرين، واثناء العدوان الثلاثي عام 1956 على مصر كانت تركيا الدولة الوحيدة في المنطقة ايدت هذا العدوان، وعارضت تاميم قناة السويس وكل السياسات التحررية

$$
\text { والثورية لمحال عبد الناصر (6). }
$$

هناك اتفاقيات عسكرية بين تركيا وبين اسرائيل جلها يركز على مساعدة تركيا من اجل مكافة نشاطات الكورد ومراقبة ومتابعة سوريا عن طريق بناء شبكات الكترونية تسمح بالتجسس على طول الحدود مع ايران وسوريا والعراق وكذلك وضع معلومات وصورالاقمار الاصطناعية الاسرائيلية، وطائرات بدون طيار لخدمة تركيا - في موابجة نشاطات حزب العالي الكوردستاني P.K.K وتبادل المعلومات في الميادين العسكرية والامنية (7)، في مقابل مساعدة اسرائيل في كيفة مكافة نشاطات منظمة تخرير

$$
\text { فلسطين والتيارات الاسلامية الاخرى . }
$$

وتقوم الدولتان بتقييم الحوار الاستراتيجي بنيها والاخطار الوقلمية عليها سوية او منفردة مرتين كل عام واقترح رئيس اركان الجيش الاسرائيلي الجنرال امنون شحاك في 13 تشرين الاول 1997 اثناء زيارته لتزكيا نظاما امنيا اقليميا مشتركا بين تزكيا واسرائيل واخرين بشكل سري وينص على تشكيل مجموعة عمل مشتركة عالية المستوى كمتها تقييم وتحليل التهديدات التي تواجه كل من تركيا واسرائيل وتنظم مناورات وعمليات تدريب مشتركة تم تزود اسرائيل الجيش التزكي بمدات المراقبة الليلية والاستطلاع (8).
- كان ذروة الفعل الواقي في كامب ديفيد تصفية ننائُ حرب عام 1973 ، فتراجع المثروع القومي ودخلت العروبة الرابطة الجامعة في وهن وتقدمت عليها هويات ذات طبيعة كيانية او تجزيئية (4). - متدخل الغرب في حرب الخليج عام 1981 ، ثم صنع حرب الخليج الثانية عام 1990 باسم النظام العالمي الجديد وفي الحربين كان النظام العربي الرسمي يضاعف

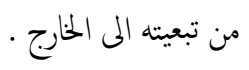
- تحول التدخل الخارجي بعد احداث ايلول عام 2001 المى استعهار مباشر لها وهو استعهار معولم امنيا وعسكريا وجاء احتلال العراق ، ضمن استراتيجية جديدة وحديثة للغرب ومعاصرة في صيغة جديدة عبر مشروع الشرق الاوسط الكبير وفي اداة ما بعد حداثية هي الفوضى الخلاقة . والغرب يطور اساليب التدخل الخارجي من عموم الدول النامية وخاصة العربية على ضوء المراحل التي مر بها الغرب لتكون الراسال الاقتصادي ، واهم تلك المراحل: أ- المرحلة الوولى هي مرحلة الاكتشافات الجغرافية. ب- المرحلة المركنتالية. ت- مرحلة الثورة الصناعية.

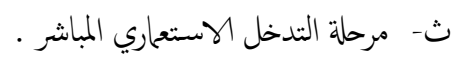

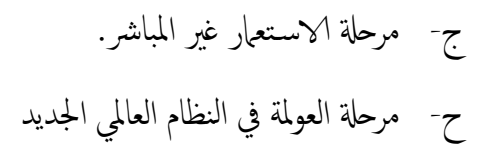
على ضوء ما تقدم يتضح ان الغرب لا يسمح ان ينافسه الاخر في ثلاث موضوعات (المعرفة، الثروة، القوة ) وهذه الموضوعات متاحة في العام العربي اذا توافرت الارادة الحرة المستقلة ونظام ديمقراطي حر ليبرالي يحترم حقوق الانسان ويحترم حقوق الاقليات ويؤسس دولة مدنية.وكذالك الدول الوقليمة تعمل على تجزئة وتشرذم الدول العربية لتبقى جغرافيها جمالها الحيوي. 7. - المبحث الوول 1.7 التحديات الومليمة الاسيوية على المشرق العربي التحديات المختملة من النظام الوقيلي الاسيوي على الدول العربية في العقود الثلاثة الماضية والعقود القادمة هي تركيا، ايران، اسرائيل، حول النفوذ والموارد و المياه و العقيدة و الايدولوجيا هي متنوعة و عديدة 
الصراع المسلح محدود كما ان من المستبعد في الظروف الراهنة ان يتحول النزاع على مياه نهر دجلة مع العراق من بحة ونهر الفرات مع سوريا من بجة اخرى الى صراع

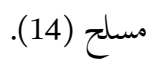
ان فشل النموذج التزكي الذي ايده الغرب وبصفة خاصة الولايات المتحدة الامريكية، لتحقيق نهضة اقليمة في الثرق الاوسط، في ان يحصل على قبول من جانب النخب

$$
\text { الثقافية والسياسية في العالم العربي لاسباب كثيرة منها: }
$$

انها دولة اطلنطية ، ترتبط مع الغرب ومع الولايات المتحدة الامريكية بحلف عسكري واستراتيجي وهي حلف شال الاطلسي . لعبت دورا سيئا في واد مشروع النيضة العربية في خمينيات وستينيات القرن

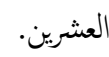
احتلت لواء اسكندرونة السورية في عام 1939 بمساعدة فرنسا . مشكلة المياه، والعلاقة متوترة بين تركيا والعالم العربي بسبب اقامة السدود والتصرف الحادي بصدد نهري دجلة والفرات بعيدا عن القانون الدولي والمعايير

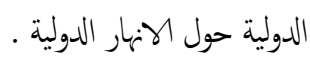

العلاقات التزكية الاسرائيلية واقامة المناورات الدورية المشتركة . كذلك تدخلها السافر في الثؤون الداخلية السورية وايواءودئ الحركات الارهابية

$$
\text { مثل جهة النصرة ودولة العراق والشام الاسلامية ( داعش ) . }
$$

ولكن التطورات الداخلية في تركيا في العقود الاخيرة وانكشاف حقيقة الاتحاد الاوروبي، بمثابة نادي مسيحي مغلق يمنع قبول تركيا فيها على الرغز من تطبيق معظم معايير الانضام الى الاتحاد الاوروبي ( مثل معيار الديمقراطية و معيار اقتصاد السوق ) ولدت ردة الفعل لدى تركيا مما ولدت توججات الهمتداد على العالمين العربي والاسلامي، وتبلورت توجحات ورؤى جديدة على خارطة السياسة التركية الخارجية وبصفة خاصة في ضوء التطورات الايجابية في الموقف التركي تجاه الصراع العربي الاسرائيلي، وبالذات الهجوم الاسرائيلي على لبنان في عام 2005 ، وعلى قطاع غزة

$$
\text { في عاي } 2008 \text { و } 2009 \text { وفي مؤتمر دافوس (15). }
$$

ويقوم الجيش التركي بمساعدة اسرائيل باجتياز حدود العراق بين حين واخر بدون

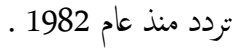
لقد احتج العراق لدى الام المتحدة، ان القوات التزكية قامت خلال الفترة من 31 تشرين الاول الى 28 تشرين الثاني من عام 1997 بـ 13 عملية خرق عسكرية داخل الاراضي العراقية واسفرت عن مقتل 13 شخصا واختطاف عثرة اخرين وتثريد (9) (9) (9) تمتد اهتمات تركيا الاستراتيجية الى ثلاث دوائر اقليمية يفرضها عليها الموقع الجغرافي، الدائرة الاوروبية، والدائرة العربية والدائرة الاسيوية الوسطى، وفي اثر التغيرات التي طرات على النظام العالمي، اطلت تركيا الى ان الارضية عهدة للالنفات الى الدائرة العربية التي تشكل ميدانا للمصاح، والمنافع الاقتصادية والمالية والاستثمرية والتجارية، لقد اعطت حرب الخليج الثانية رقا جديدا لسياستها العربية والشرق اوسطية (10). فنحركت على ثلاث محاور ، الامن الهقيلي، والمجال الاقتصادي والمياه، لقد بلغت المعونات ، والهبات العربية التي ارسلت الى تركيا منذ بدء ازمة الخليج حوالي 5، 2 مليار دولار امريكي (11). (- - (11). مع التخطيط لفتح الاسواق امام المصنوعات التزكية، وتشجيع الراسال العربي على زيادة استثاراته في تركيا، واضافة الى ذلك حصلت تركيا على مكسب ذي طابع استراتيجي تمثل في اسهام مالي كبير في صندوق الصناعات العسكرية التزكة الذي يبلغ راسماله $3 ، 5$ مليار دولار امريكي. فقد اسهمت كل من السعودية والكويت بمليار دولار امريكي في حين اسهمت الامارات العربية المتحدة بنصف مليار دولار امريكي، اما الباقي من راسال الصندوق مقداره مليار دولار امريكي فقد توزعته مناصفة بين تركيا والولايات المتحدة الامريكية (12). يشكل نهري دجلة والفرات ورقة تركية ضاغطة على سوريا والعراق تهدف من وراء ذلك الى بلوغ اغراض مختلفة، ولقد ادى الطريق الذي اتبعته تركيا في استثاره مياه الفرات الى حرمان سوريا والعراق من جزء كير من حقها القانوني والثابت في مياه نهر القرات حتى اصبح هذا المثروع التركي اشبه بالسلاح السياسي بهد حياة وامن الدولتين المجاورتين ويعتدي على حقوقها المشروعة ويضر بالمصاح المشتركة التي تجمع

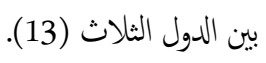
في ضوء ما تتصف به العلاقة التزكة العربية بصورة عامة من حذر وعدم الرغبة في تصعيد التوترات وتعقيد المشكلات الى حد استخدام القوة او التهديد بها فان احتلالات 
مضافا اليها المتغرات والمعطيات التي استجدت بعد حرب الخليج الثانية، وافرازات مرحلة التسوية بين الطرفين العربي - الاسرائيلي بطريقة الثفاوض، ستبقى هذه النظرية قائمة ومستمرة ومتطورة وبخاصة ميزة التفوق العسكري على القوى العسكرية العربية والقدرة على دفع الحدود عبر الجغرافية للامن الاسرائيلي الى ما وراء حدود الوطن ركن

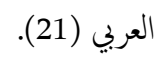

في ضوء نظرية الامن الاسرائيلي هذه ذات الاذرع الضارية الطويلة من الحكمة ان تعمل اسرائيل لترسيخ سيطرتها وهيمنتها من خلال استثمر التناقضات القائمة تنشا بين الدول العربية من بجة ودول الجوار الجغرافي من بجة اخرى .

ان طبيعة الاستراتيجية الاسرائيلية التي تفرض على الدول العربية هي العمل الدائم على تنتيتها واهدار طاقاتها ومنع قيام وحدة بنها وتعتبر الوطن العربي منطقة واحدة، يلزم تجزتها وشرذمتها وبهذا تقوم هذه الاستراتيجية على الانفراد بكل قطر عربي بعيدا عن

$$
\text { الاقطار الاخرى (22). (22) }
$$

وان هذه التناقضات من حيث وجودها ونشويها وتعقدها وتطورها وتحريكها تدخل ضمن اهتمات ومفردات الامن القومي الاسرائيلي، وفي حالة سكون او تحرك بطيء في الوقت الراهن، فان احتالات تازم بعضها ودفعها الى المواجهة ارادتها قائمة وخاصة حينا تطلب بعض الظروف ذلك، او تتوافر العوامل الكافية لذلك، واذا كانت المعطيات والمتغيرات التي طرات على النظام العالمي، ونتائُ حرب الخليج والتطورات التقنية الحديثة (تكنولوجيا الاسلحة)، فدفعت اسرائيل الى مراجعة عقيدتها العسكرية ، فان

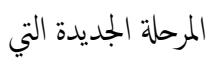

دخلت الهيا الصراع العربي - الاسرائيلي، يوم الثلاثون من تشرين الثاني عام 1991 في مؤتمر السلام للثرق الوسط بمدريد عاصمة اسبانيا، كان العامل الاهم والككر الحاحا في اقرار تلك المراجعة ، ذلك ان اسرائيل كانت وما زالت تعتقد ان السلام

الاسرائيلي يجب ان ينثق من رعاية مصالحها واهدافها مع العرب (23). ويكن ان ينجز ذلك عن طريق استرانيجية القوة ، وانها تستطع من خلال هذه الاستراتيجية تحقق الهيمنة والسيطرة، وان تعرض حلولها وهي تريد ان يتحقق ذلك في اطار ان تبقى اسرائيل الدولة النووية الوحيدة في منطقة الثرق الاوسط، ويكن تحليل ذلك من الادبيات العسكرية الاسرائيلية الرسمية والشفاهية العامة ،ويلاحظ ان هناك اجلاعا ازاء المسائل المتعلقة بمستقبل التوازن والامن الوقلميين جوهرة ضرورة
هناكُ نقطة همة يجب الاثشارة اليها ،لاها تلقي الضوء على دور تركيا في المنطقة ، وهي ان اسرائيل ترى في تركيا ثقالا مضادا لايران والعراق على السواء وفي حال الضرورة ثقلا مضادا لسوريا (16). 2.1.7 المطلب الثاني: التحدي الاسرئيلي

تتمثل بالنسبة الى اسرائيل في استخدام القوة العسكرية لمزيد من اقتطاع اراضي عربية من الاقطار المجاورة او اجبارها على توقيع معاهدات السلام وفتح اسواقها للصناعات الاسرائيلة او لاثارة القلاقل الداخلية ومحاولة تفنيتها الى دويلات طائنية او لاجهاض اية محاولة وطنية لزيادة القدرات العسكرية والاقتصادية والتكنولوجية او تاسيس انظمة

ديمقراطية (17).

ان السياسة الاسرئيلية قائمة على التوسع واحتلال الاراضي العربية المجاورة، وسعيها الدائم على فرض شروط سلام على جيرانها العرب وفرض ارادتها وقرارها في عموم المنطقة مع ما يمثل ذلك من وراثة بدور السلطنة العثانية او ما عرف بالمسالة الشرقية

وان هذا النزاع تزامن مع نظام القطبية الثنائية وهكذا ارتبط هذا الصراع بالصراع الدولي، إذ توافتت الادارة الامريكية مع طموحات اسرائيل لاخضاع المنطقة تحت سيطرتها لا سيا بعد تصاعد الاهمية العظمى لدور الطاقة " النفط والغاز " في رسم السياسة الاقتصادية في العالم، هذا من بجة، ومن ججة ثانية دع الاتحاد السوفييتي السابق اللامحدود للحركات القومية والوطنية التحررية في الوطن العربي لموابجة اسرائيل والنفوذ العربي في الوطن العربي (19). يعد الصراع العربي - الاسرائيلي من ابرز المؤشرات في العلاقات الدولية خلال القرن العشرين بحروبه الستة واعتداءاته المنكررة ومعاركه الكثبرة ووقائع الجبروت الاسرائيلي، وانطوائها على اغراض توسعية مستقبلية جغرافية، ونقوذيا واقتصاديا وتكنولوجيا، مع ذلك تحمل ملامح التسويات الثنائية التي بلنتها بعض الاطراف العربية وبخاصة الطرف الفلسطيني مع اسرائيل بعدا زمنيا طويلا ينطوي في غضونه على احتالات متعددة وختلفة ومتناقضة وستبرز مشكلات تفكيك العلاقات والاثار والنزسبات الاحتلالية والاعتدائية التي بلغ عمرها اكثر من قرن بروزا حادا ومعقدا في بعض جوانها وستنشا حالات جديدة من العلاقات (20). وفي غضون ذلك ايضا ستبقى نظرية الامن القوي الاسرائيلي قائمة بعقماتها، واسسها وعناصرها التي انتهت الهيا في ختام المرحلة الراهنة في الحروب العربية - الاسرائيلة، 
لاشك ان اسرائيل لعب دوره في التدهور الذي المبمحاولة النهة العببية فقدكان هو الاداة التي وبجت الضربة العسكرية الى الدولة القائدة لهذه المحاولة في عام 1967 واستطاع هذا الكيان على الرغ من الانجاز العربي في حرب الاستنزاف عقب عدوان عام 1967 وحرب عام 1973 ان يثابر على سياسته التوسعية بسند امريكي مطلق وفي هذا الاطار ، حدث الاختراق الاسرائيلي الكبير للدول العربية بتوقيع معاهدة السلام مع مصر في عام 1979 والاردن في عام 1994 ـ ونجح في ضرب واسقاط المشروع النووي العراقي في مستهل ثمانينات القرن الماضي · وما تبع ذلك من هرولة غير مبررة من قبل عدد من الدول العربية باتجاه اسرائيل ، الامر الذي عزز الانقسام العربي بشان سبل الموابحة مع اسرائيل ، وعلى الرغخ من ان المقاومة الفلسطينية والمقاومة اللبنانية قد حققتا انتصارات هامة في هذه المواجهة وبصفة خاصة بداية الالفية الثالثة، ولكن غياب ظهير عربي قوي لما واستشراء الانقام الداخلي بين فصائل المقاومة الفلسطينية قد مثلا قيدا ، واضحا على هذه المقاومة البطولية

\subsection{7 المطلب الثالث : التحدي الايراني}

كانت ايران في زمن جزء لا يتجزء من المشروع الامريكي - الغربي - الاسرائلي ، المناهض لامال الامة وغاياتها ، وعندما نجحت الثورة الايرانية في عام 1979 ، تبادلت ايران الادوار مع العرب المد القوي في الستينيات القرن العشرين غير ان التشدد القوي الواضح للثورة الايرانية والثناقض الواضح بين مشروعها الاسلاي والنظم العببة عامة و الخليجية خاصة اوجدت احتقانا في العلاقات العربية - الايرانية بلغ ذروته في اعوام 1980 - 1988 باندلاع الحرب العراقية الايرانية ، وكانت اطول حرب نظامية دولية يشهدها العالم بعد الحرب العالمية الثانية، وقد تركت تلاك الحرب اسوا الأثار في تدمير مقومات القوة العربية وتعثر مسيرة الامة على طريق التنمية ، وامكانات عمل عربي ايراني مشترك لموابجة محاولات الهيمة الامريكية - الاسرائيلية (30). ايران تسعى الى كلى توسيع نقوذها الوقليم من خلال التمدد السياسي الخارجي، فهي طورت علاقات وثيقة مع سوريا ومع فاعلين من غير الدول كلاحزاب الشيعية في العراق، وحزب الله في لبنان والحوثيين في اليمن، وحركة حاس في فلسطين (31). ومن منظور بعض النخب السياسية العربية، فان ايران تسعى الى تشكيل هلال شيعي يمتد من ايران المى بلاد الشام، بما يشكل خطرا دائما على المنطقة العربية وخاصة الجزيرة العربية (32).
الاستمرار صوغ الاستراتيجية العسكرية - الاسرائيلة على اساس الخيار الاسوا

وان الوسيلة الوحيدة لبناء تلك الاستراتيجية هي الثفوق العسكري وما يسميها الاستراتيجيون العسكريون الرادع النووي .

والاستراتيجية الاسرائيلية الاخرى هي موققها الرافض لاندماج بعض الحركات الاسلامية او استلامحا السطة في النظم السياسية العربية وعبر عن رؤية تشكك في منطق وحكمة الادماج والمكاسب المتوقعة منه يرى اسرائيل ، ان هذه الحركات ما تزال تبني رؤية مناهضة للغرب يصعب تغيرها ، ولا يمكن الوثوق بتغيرها نحو الحوار والتعاون، فنزعة مناهضة الغرب السائدة في هذه الحركات هي ذات طبيعة ثقافية ، مناصلة في رؤيتها للعالم ، تضع المسلمين في موابحة مؤامرة غربية شاملة، بما يفرض الصراع بين قوى الخير والشر - والاسلام الذي تعبر عنه هذه الحركات من وبجة نظرها هو الذي ينبني

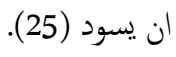

والغرب الذي يمثل العدو المتامر الذي يسعى الى فرض هيمته الثقافية والاقتصادية والفكرية على المسلمين، ضمن هذه الرؤية، فان هذه الحركات الاسلامية التي ينظر اليها على انها معتدلة، تقود المواجهة مع الغرب ومعاداته، وتنشر الفكر التامري ، ويستدل الخطاب الاسرائيلي على ذلك، مثل جاعة الاخوان المسلمين أنموذجا، التي ترى ان الحرب على الارهاب هي الحرب على الاسلام والمسلمين، وانها بالرغ نبذها العنف داخليا ظل موقنها من الهجات الارهابية غامضا، وحتى بعض الزعامات في الحركات الاسلامية التي تبدي توبجات معتدلة فيا يخص اندماج المسلمين في الغرب فانها تتبنى توجهات راديكالية ازاء قضية الجهاد (26). ان الحركات الاسلامية بمختلف اطيافها، تتبنى هدف استئصال اسرائيل ، كجزء من ايديولوجيتها حتى تلك الحركات التي ينظر الهيا على انها مؤهلة للاعتدال فايديولوجية تلك الحركات لحسب الفهم الاسرائيلي لا تتسامح مع وجود كيان غير اسلاي في المنطقة

واسقاط حكومة (مرسي) خير مثال باسم مظاهرات 6/30 عام 2014 الذين احتشدوا ثلاثون مليون، كانت استراتيجية خطط لها اسرائيل والغرب ونفذها الجنرال السيسي.

ولهذا فن الطبيعي ان تبقى اسرائيل لأمد غير منظور الخصم والتحدي الرئيس للامن القوي العربي (28)، وللجيو سياسية العربية . 
وكان اندحار القوة العسكرية والاستراتيجية العراقية عام 1991 بمثاب خروج العراق

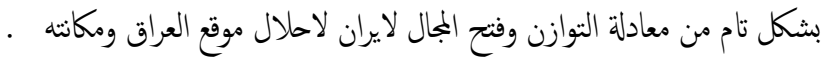
اما خخاطر الطموح الايراني او الجيو - سياسي الايراني على الدول العبية من اجل ان يحتل مكانة دولية اقليمة كبرى شرعت في تنفيذ برامج طموحاتها الاستراتيجية والشاملة. اعادة بناء قواتها العسكرية مع التركيز على القوات الجوية والبحرية، والاسلحة

$$
\text { الصاروخية الباليستية البعيدة المدى . }
$$

تويل جزيرة ابو موسى المملوكة لدولة الامارات العربية المتحدة الى قاعدة عسكرية جوية وبحرية ضخمة ،ولم تكنف ايران ببناء ترسانة عسكرية ضخمة، بل ركزت على

بناء مفاعل نووي والحصول على التكنولوجيا النووية من الصين وروسيا . والهند وباكستان الامر الذي حول ايران الى مصدر خطير من مصادر التهديد الاقليم، سواء على مستوى الامن القومي العربي او على مستوى الامن الوقليم الشرق

وليست من شك في انه ما اكتسبته ايران من مزايا استراتيجية على حساب القوى العربية والامن القومي العربي ، والدور الهقيلي العربي وتماكك الدول العربية ، وهي تواصل جحودها في هذا الشان الامر الذي يؤكد عودة الاططاع الفارسية القديمة الى الحياة، مضافا الهيا اطلاع الثورة الايرانية ، لذلك فهي تبدي معارضتها القوية المستمرة لقيام اي نظام عربي للامن القوي في منطقة الخليج يتجاوز نطاق دول مجلس التعاون

$$
\text { الخليجي، وفي هذا الاطار عارضت ايران بشدة وثيقة دمشق (36). }
$$
كذلك قامت ايران في 30 /كانون الاول من عام 1971 باحتلال الجزر الاماراتية العربية بحجة اقامة قاعدة بحرية وجوية وبرية في جزيرة ابو موسى وطنب الكبرى وطنب الصغرى ، ستمكن ايران من مراقبة الحميط الهندي الى الخليج العربي لتصدير النفط الهيراني المى الخارج بانسيابية ـوتم احتلالها بمعاونة بريطانيا راعي الخليج العربي مع امريكا خارقة قواعد القانون الدولي ، اضافة الى افتقارها الى سند تاريخي يؤيد وبهة نظر ايران (37). على ضوء ما تقدم ، ما زال النظام العربي غير قادر على ان يجد المعادلة المتوازنة والصحيحة لعلاقة بايران على النحو الذي يعظم القواسم المشتركة ويحفظ الامن القوي

$$
\text { العربي والمصاح العربية في ان واحد (38). }
$$

كانت وما تزال وستبقى في المستقبل القريب او على الاقل في العقود الثلاث او الاربعة القادمة ايران دولة اقليمية و اقوى دول المنطقة وساعدها في ذلك العوامل التالية :
وفي عام 1982 تبلور النفوذ الايراني في المنطقة عبر ميزانية عسكرية سنوية تقدر بـ 4 ملاينن دولار امريكي. ان سوريا هي القاعدة الامينة والنافذة الوحيدة لها للاطلال الايراني على البحر الابيض المتوسط ودع حزب الله، والمنظلات الفلسطنية والحوثيين في اليمن ، والشيعة في الطائف والشيعة في العراق والفراغ السياسي وعدم اعتراف الدول العربية بالنظام السياسي الجديد في العراق تمددت ايران لملهيها (33). بدات ايران تمنح هذه الحركات والاحزاب دع مادي ومعنوي سنوي بما يؤدي الى زعزعة الاستقرار في هذه الدول من جانب وتحقيق ايران لمصالحها الوقليمية والدولية من جانب اخر حيث تؤشر الممارسة العملية المى استخدام النظام الايراني لورقة الاقليات الشيعية في اقطار الخليج العربي لزعزءة الاستقرار من خلال تجنيد شيعة البحربن والكويت في تنظيمات شيعية ، حزب الله في الكويت ، والجبهة الاسلامية لتحرير البحرين ، ودورها من دع مستمر نظام الحكم واقامة جمهورية اسلامية على غرار ايران ومن خلال ممارسة العنف السياسي في الكويت ومحاولة الانقلاب والتمرد في البحرين

اذن على ضوء ما تقدم يمكن القول ان ايران بعد الثورة الاسلامية ، باخذ شكل الهيمنة السياسية ، الايديولوجية اي الفكرية على العراق والبحرين والحوثيين ، وجنوب لـون لبنان والابتزاز الاقتصادي لبقية اقطار الخليج، اما في شكل مساعدات وهبات او بنتح ابوابها للعمال والبضائع الايرانية، وكذلك التهديد العسكري، من خلال المناورات والاستعراضات المتكررة في الخليج ومضيق هرمز، واستخدام اجيال جديدة من الصواريخ الباليستية البعيدة المدى والطائرات بدون طيار . لا شك ان السياسة الايرانية في حقبة بعد حرب الخليج الاولى لاحت بشكل واضح بانها ساهت بقدر كير في تفكيك واضعاف الدول العربية كهدف يسعى النظام الايراني الى تحقيقه من اجل ازالة المعوقات امام الاطاع الايرانية في الدول العربية وتجددت وانتعشت بسقوط العراق ، وتحولت الى موقع الريادة لتصبح دولة اقليمة كبرى تسيطر على المناطق الميطة بها ويمتد نفوذها الى المناطق البعيدة (35). وتستغل الدين والعقيدة ، والمذهب، من اجل تصدير الثورة الايرانية للخارج ، باستخدام شتى الوسائل المشروعة وغير المشروعة في محاولة السيطرة من الداخل عن طريق نظام حكم يكون موالي لها . 
جديدة على راسها الصين وامريكا واسرائيل الى ساحة التنافس داخل القارة الافريقية ، بدا بانحسار النفوذ والدور العربي الريادي في هذه القارة وبدا الحضور العربي - الافريقي اضعف من ان يولد تعاضدا عربيا - افريقيا ، من اجل نهضة شاملة وتضامن دائم (40). لذا سوف نحلل الموقف الافريقي او التحدي الافريقي من خلال ثلاث مطالب :

\subsection{8 المطلب الاول : التحدي الاثيويي}

قامت اثيوبيا باحتلال اقليم اوغادين الصومالي في عام 1955 ، وما زالت حتتظة بهذا الاقليم(41). ومنذ سقوط ( محمد سياد بري )، ونشوب الحرب الاهلية في البلاد وبروز حركات الاسلام السياسي تدخلت اثيوبيا اكثر من مرة بضوء اخضر من امريكا ومرة من الاتحاد الافريقي ومرة تحت عنوان حاية الامن القوي الافريقي، واحتلت عدة اقليم على الحدود واحتلت العاصمة مقديشو اكثر من مرة ، وما زالت قوتها تتمركز

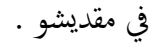

اقامت اثيوبيا العلاقات مع اسرائيل بشكل رسمي من عام 1956 إذ تم فتح اول قنصلية اسرائيلية في اثيوبيا إذ اتسمت بالجدية والفاعلية لتسهيل تممة التغلغل الاسرائيلي في اثيوبيا وفي مختلف المجلات وفي عام 1961 فتحت سفارة لها في اديس ابابا، ومن خلال ذلك نشطت الزيارات والوفود المتبادلة على خختلف المستويات الرسمية وغير الرسمية ومن ابرز تلك الزيارات الزيارة التي قام بها الامبراطور (هيلا سلاسي) اسرائيل عام 1960 ، قام بالمقابل الوزراء والوفود البرلمانية الاسرائيلية بزيارة اثيوبيا كزراء المعارف والزراعة والري والقادة العسكريين لغرض تمتين الصلات الاسرائيلية الاثيوبية بشكل

$$
\text { يخدم مخططات التغلغل الصهيوني في افريقيا (42). }
$$

- على الصعيد الاقتصادي: اصبحت ميدانا مها للنشاط الاقتصادي الاسرائيلي نتيجة تتع اسرائيل لفائض كير من الاموال ، وحاجة اثيوبيا للعون الملالي والعلمي الاسرائيلي. اضافة الى ذلك ان هذا التغلغل يؤمن الموارد الزراعية والاسواق لبضائعه كما انه يمثل تمهيدا لتغلغله السياسي (43). وبعد اثيوبيا سوقا رئيسيا للصناعات الاسرائيلية ، ومن خلال ملاحظة الجدول التجاري نجد منذ عام 1965 يميل لصالح اسرائيل حيث بلغ جمل قيم الصادرات الاسرائيلية الى اثيوبيا ما يقارب 635،1، مليون دولار امريكي. اما على الصعيد العسكري: فقد تميزت بالمتانة خصوصا من عام 1961 إذ استطاعت اثيوبيا الاستفادة من الخبرات الاسرائيلية في حرب العصابات لمجابة
الثاثير العقائدي في بعض المتمعات العربية. القدرات الاقتصادية الهائلة . القدرات البشرية الهائلة . الموقع الاستراتيجي لايران نتيجة تحكها في مضيق هرمز. القدرات التكنولوجية وتقنية المعلومات .

استيراد التقنية العسكرية وتكنولوجيا السلاح من كوريا الشمالية ودول اسيا الوسطى والهند وباكستان وروسيا الاتحادية والصين .

محاولاتها الحثيثة لامتلاك الاسلحة النووية (39).

وعليه، يتين ان هذه المعطيات تطالب بالحاح الفكر السياسي الاستراتيجي العربي ، اكثر من اي وقت مضى بمواصلة البحث الجاد والمشترك ، والتفكير القومي الديمقراطي المستنير في المستقبل الوقليمي وتنشيط الدور العربي الفعال والضروري لموابجة كل التحديات المتصاعدة ، ليس فقط على مستوى دول الاقليم غير العربية، وكذلك على مستوى عموم الشرق الاوسط. وتحاول ايران ان تحل موقعها الوقلي السابق في عهد الثاه لتصبح القوة السائدة الاولى في الخليج . له ولا شك ان استمرار الانحدار القوي والسياسي والثقافي يعني تعاظم الدور الاقليمي

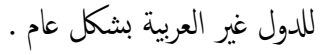

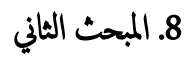
1.8 التحديات الاقتلمية الافريقية على المغرب العربي على صعيد القارة الافريقية ، اخفق النظام العربي في تحقيق علاقات تعاونية مستقرة مع الجانب الافريقي تجعل من الطرفين حليفين في السعي نحو النهة والتصدي لمحاولات الهيمة .كان للنظام العربي في مرحلة المد القوي في خمسينيات وستينيات القرن العشرين دوره الفاعل في معارك التحرير الافريقية ، غير ان هذا الدور واجه دوما عقبة التغلغل الاسرائيلي في افريقيا وعلى الرغخ ما بدا من النعاون العربي - الاهريقي ، بلغ ذروته بعد القمة العربية - الافريقية في اذار من عام 1977 ، الا ان الامال المعقودة على هذا التعاون ، سرعان ما انخسرت مع بداية الاتقسام العربي حول التسوية مع اسرائيل في السنة نسها ومع تفام الاقتسام العربي واستمرار النشاط الاسرائيلي ودخول قوى عالمية 
نهر النيل حيث يتوقع ان تقل امدادات المياه بما لا تقل عن 20\% وان تقل الطاقة

الكهربائية بـ 40\% وفقا لتقرير اعدته لجنة من خبراء الزراعة والري في مصر (47). واشارت صحيفة (فاينانشال تايمز) الصادرة يوم الاربعاء 13 نوفبر من عام 2013 ان بناء سد النضة الاثيوبي يؤثر على الامن القوي المصري ، واهتمت الصحيفة بتصريحات رئيس الوزراء المصري الاسبق هشام قنديل ، الذي وصف حصة مصر من مياه نهر النيل بانها امن قوي وان بناء السد الاثيوبي عملا من اعمال التحدي ما يتسبب في توتر بين الدولتين وبهدف السد لانتاج طاقة كهرمائية تبلغ طاقتها حوالي 6000 ميجا واط ، حيث يعرض معظمها الى البيع ، حيث تشتري السودان بالفعل الطاقة من اثيوبيا واضافت الصحيفة ان المصريين وصلوا المى درجة الغليان وبعد تحويل اثيوبيا جزءا من النيل الازرق تمهيدا للمشروع حيث يتهم العديد من المصريين ، اسرائيل ، والولايات المتحدة الامريكية بالوقوف وراء بناء سد النهضة الذي يجري بناءه من قبل شركة

الهندسة الايطالية ساليني (48).

نشرت صحيفة (لوس انجلوس تايمز الامريكية )تقريرا عن ازمة مياه النيل خصوصا بعدما بدات اثيوبيا بناء سد النهة ، حيث قالت ان مصر تتاربح داخل التهديد الذي شكله خطر الدول الافريقية بشان مياه النيل فبلدان المنبع خصوصا اثيوبيا لم تعد ملتزمة باتفاقيات الاستعحر بشان حقوق المياه وتتجه لحسب حصص اكبر من مياه الري والكهرباء لتوفير متطلبات الرفاه الاثيوبي (49). و قالت الصحيفة ان التحدي الاكبر امام القاهرة هو سد النهضة، الان حيث يقدر الخبراء ان مشروع الطاقة الكهرومائية ، يكن ان يقلل من تدفق النهر الى مصر بنسبة تصل الى 25\% خلال السنوات الثلاثة التي سيحتاج اليها لملئ الخزان خلف السد . ونقلت الصحيفة عن (هاني رسلان ) الخبير في مركز الدراسات الاستراتيجية والسياسية المصرية ، (اذا اكتمل بناء السد ستتحول اثيوبيا المى عدو لمصر واضاف ان مصر سيكون لها الحق قانونيا في الدفاع عن نقسها من خلال الحرب ) وان جوهر الصراع بين الدول الفقيرة وخاصة مصر واثيوبيا هي المياه - مياه النيل (50). لم تكن مفاجاة ان يعلن رئيس الوزراء الاثيوبي ضرورة ان تشارك مصر والسودان بلاده في بناء سد النضة وان الاعلان عن النسب المئوية لاكمال السد ارقام غير صحيحة وان عملية تحريك المعدات المى موقع السد واتمام مساكن المهندسين والعمال والمكاتب للابهزة العاملة في انشاء السد، وان عملية نقل كيات هائلة من الاتربة وحفر قناة التحويل يكن ان يبلغ نكاليفها ربع اجلالي تكاليف بناء السد (51).
حركة التحرر في اريتيريا ، إذكانت اريتيريا انذاك مستعمرة اثيوبية ، وكذلك مجابة الدول العربية المجاورة مصر ، السودان ، الصومال (44). إذ شملت هذه العلاقات العسكرية قيام اسرائيل بتدريب القوات الاثيوبية المسلحة بمختلف صنوفها حيث بلغ عدد المندربين ما يقارب 15 الف جندي .بالاضافة الى ذلك قامت اسرائيل بارسال الخبراء والمستشارين العسكريين ، وشغل قسم منهم المناصب العليا في الدولة في الاستخبارات وامري المدارس العسكرية (45). و الصحة والشباب من خلال تقديم المنح والخبرات الفنية في بجال التعليم ، كما تم ايفاد الاساتذة والمدرسين للجامعات الاثيوبية للاشرف على طلبة الهندسة في

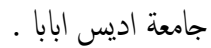
- ماما على الصعيد الهملاي والسياحي: فقد سعت اسرائيل الى التغلغل في المناصب العليا في اثيوبيا نجح في ذلك باسناد من ابجزة المخابرات الاسرائيلية والامريكية حيث اتضحت سيطرته على ابجزة الاعلام الاثيوبية وتوجيه الراي العام الاثيوبي نحو تاييده في موقفه ضد الدول العربية . - اما على الصعيد الزراعي: برزت جهود اسرائيل حول بناء سد عملاق على نهر النيل ومنع تدفق المياه الى السودان ومصر وخلق ازمة مياه بين البلدين تحويل

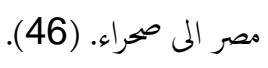

اذن التحدي الجيو - سياسي الاثيوبي على الوطن العربي بالاضافة الى علاقاتها المميمة مع اسرائيل هي اقدامحا في الاونة الاخيرة على بناء سد النهضة على نهر النيل لا تزال سد النضة الاثيوبي تطنى على كثير من الملفات على الساحة المصرية ، نظرا الى لى خطورتها الحالية والمستقبلية على مستويات عدة والانعكس مع حجم الجدال المثار في مصر حاليا بخصوص تلك المعضلة التي يبدو ان نظام المكي مرتبك بشانها، ولايعرف كيفية التصرف حيالها فان القضية ما زالت تخظى بتغطية واسعة من جانب وسائل الاعلام داخل القارة السمراء وخاربحا . اكدت صحيفة (واشنطن تايمز الامريكية ) ان مصر باتت همدة بسبب ذلك السد خاصة مع بدء تحويل اثيوبيا بالفعل لمياه النهر الازرق تمهيدا لاتخاذ مجموعة من الخطوات الفعلية التي تري الى بناء السد لتوليد الكهرباء بقيمة قدرها 42 مليار دولار امريكي ، واشارت الصحيفة الى ان ما تخشاه مصر هو ان يعمل السد على تقليل حصتها من مياه 
ب- 2-العوامل الثقافية والعرقية (58): استندت ليبيا أيضا بضم اوزو إلى الاصل ليبيا إلى العوامل الثقافية والعرقية والدينية لكون الساكنين فيها من قبائل البدو الرحل من العرب، والتبو ، والطوارق وهذه الاثتيات هم مسلمون ولمم ثقافة عربية

إسلامية.

ت- 3-العوامل الأمنية: لممايتهم وتأمين سلامتهم لكون تشاد كانت دولة غير مستقرة حدثت فيه الحروب الاهلية والإنقلابات. ان الحرب الاهلية التي دارت في تثاد وتداعياتها على ليبيا لكي يكون خط الدفاع الاول ضد محاولات الدول الغربية (فرنسا، الولايات المتحدة الامريكية واسرائل) من خلال التشاد( الندخل في الشؤون الليبية) وخلق مشكلة الاوزو لكي تخلق صراع بين ليبيا وتشاد - لذا اسرعت ليبيا بالسيطرة على الاقليم من 1973(59) . ث- 4-العوامل الاستعارية: تم رسم الحدود بشكل تعسفي بين دول عالم الثالث( الدول النامية) من قبل دول التحالف في 1919 فتكدست فيه الأعراق والاجناس والأديان والمذاهب بشكل غير عقلاني، دون أي مسوغ قانوني او ثقافي او اخلاقي بل اعتمد المؤتم على خطوط الطول و العرض على الخزيطة فقسمت قوميات واديان بين عدة دول حيث كانوا أكثرية في جغرافيته و بعد التقسيم اصبحوا أقليات وتداعيات ذلك لم يحقق الاندماج الاجتمعي والوحدة الوطنية بسبب الحكم المستبد والقمع والاضطهاد بالقوة وبها رسمت الحدود الليبية مع الجيران وخاصة تشاد بشكل تعسفي- مما زرع الصراع الكامن بين ليبيا وجيرانها

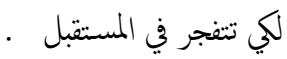
العوامل السياسية : الرئيس الليبي السابق (معمر القذافي) عقد اتفاق سري مع الرئيس التشادي (فرانسوا تومبالباي) في عام 1972 فواها، تتنازل التشاد بموجها على قطاع اوزو للحكومة الليبية وكذلك تقطع علاقاتها الدبلوماسية والاقتصادية

$$
\text { مع اسرائيل مقابل } 28 \text { مليون فرنك فرنسي. }
$$

وفي المقابل تتوقف ليبيا عن تمويل الجبهة الوطنية لتحرير التشاد بالسلاح والمال(60)، ولاتتدخل في الشؤون الداخلية التشادي ولا يساند طرف على حساب الاطراف رل

$$
\text { الاخرى وان لا تتدخل في تاجيج الحرب الاهلية(61). }
$$

اما مواقف بعض الدول العربية من الصراع وخاصة مصر والعراق هي كما يلي:
الا ان ما تبقى من الاعمال الككثر احتياجا المى التقنيات العالية مثل الجسم

الخرساني للسد الذي يبلغ ارتفاعه حوالي 150 مترا وهو يماثل ارتفاع مبنى يتكون من 50 طابقا . محطة توليد الطاقة الكهربائية التي تشمل، التوربينات والاجهزة والمعدات الميكنيكية البالغة التعقيد والتي تتناج المى خبرات عالية في التوريد والتزكيب والتشغيل والصيانة كل هذه الكعال البالغة الاهمية لم يبدا فيها العمل بعد (52). وان التمويل المتاح قد لا يكني لتحقيق الحلم القوي بتشييد هذا العمل بميزانيته تعتمد فقط على الاكتتاب بين المواطنين وتدبير المبالغ من وفورات موازنة الدولة . لذا قد يكون السبب وراء العرض الاثيوبي للمشاركة من مصر والسودان هو عدم القدرة على التمويل الذاتي وقد يكون السبب وراء العرض ايضا وضع الدولتين امام امر واقع يظن رئيس الوزراء انها لن يقبلا به لان لما مواقف سابقة رافضة لفكرة انشاء السد من الاساس او ان النغيرات الجديدة في مصر واسقاط مرسي وفرت اجواء او واقع الذي نعيشه اليوم قد تجعل متخذ القرار يعدل من المسار التفاوضي للبلاد بعد نجاح ثورة 30 يونيو (53). او ريما لكان العرض جاء بسبب عدم القدرة على التمويل الذاتي ماليا والتي تساعد اثيوبيا في تشييد السد وبسبب الضغط العربي - السعودي ، الاماراتي ، الكويتي، الفعال على الجانب الاثيوبي بعد قيام ثورة 6/30 وهو احد النتائُ المباشرة لقياها (54). 2.1.8 المطلب الثاني: التحدي التشادي - الليبي عانت ليبيا من نشوب نزاعات حدودية متعددة مع البلاد المجاورة وخاصة تشاد بسبب رسم الحدود اللبيي بشكل تعسفي من قبل دول الحلفاء في فرساي. شهدت عام 1994 ، الجولة الاخيرة من نزاع الحدود بين ليبيا وتشاد الذي اندلع منذ عام 1973 ولجات الطرفان الى التحكيم الدولي ، واقرت محكم العدل الدولية سيادة تشاد على شريط اوزو بسبب الضغوطات الغربية على المككة لصالح تشاد وموجيها انسحبت ليبيا من الشريط في 30 يوليو عام 1994 (55). والتحدي التشادي مع ليبيا هي على قطاع أوزو(56) الحدودي بين البلدين وتطالب ليبيا بملكية هذا القطاع-واستندت في مطالبنها بعودة شريط قطاع اوزو الى ارض الوطن ليبيا. الى عدد من العوامل منها. أ- العامل التاريخي(57): كانت منطقة اوزو خلال الحكم العثاني تابعة لل ليبيا كذلك خلال فترة الاستعار الايطالي ل ليبيا، قامت فرنسا التي استعمرت تشاد بالتنازل عن قطاع اوزو الحدودية إلى إيطاليا. 
وتسببت في اضرار مادية بالغة للمتلكات الموريتانيين في السنغال ونهب وسلب

سلعها ومدخراتها والاستيلاء على مواشيه(64).

المرحلة الثانية: بسبب إهال وتريث الموقف الحكوي السنغالي لمنع الغوغاء والمؤيد للحرب وراء الكواليس قام بها السنغاليون امام انظار الشرطة والامن السنغلاي من تخريب متعمد وقتل وسحل كل الموريتانين على الشوارع وتدمير المصاح الموريتانية مما اوصلت الازمة إلى نقطة اللاعودة .ونشوب الحرب بين البلدين اسبابه في الظاهر نزاع حدودي على تقسيم النر(65) وعلى المراعي وصيد السمك ولكن هنالك اسباب متعددة يككن تحليلها وإرجاعها إلى النقاط الخلافية

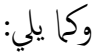

O هنالك حساسيات عرقية قديمة بين المجموعات العرقية الاثنية غير العربية من

الزنوج والسنغالين والقبائل العربية والبربرية الموريتانية في الدولتين.

O تبنت السنغال فكرة الزنوج وإقامة الدولة الخاصة بهم متمثلا بتبني الرئيس السنغالي ليوبولد سيدرا سينغور والذي يعد من ابرز دعاة ومنظري هذه الفكرة والذي كان يأمل لوحدة العرق الزني في المنطقة وتحقيق هويتهم الثقافية والسياسية والجغرافية والاقتصادية الافريقية (66 ) . قامت السنغال بمساعي جدية للقومين الزنوج في موريتانيا حيث أنشأ وعلى أراضيها تنظيلهم المتعددة ثم ساندت المعارضة للحكومة الموريتانية والتي توحدت لاحقاً في حركة تحرير الافارقة من موريتانيا تحت جبهة (Flam) فلام وتناغز فكرة الوطن القومي الزبجي المدعوم من السنغال مع الطرح الفرانكفونيا الاستعحاري السابق والذي عمل بقوة على فصل الزنوج الموريتانيون تعليمياً

$$
\text { وثقافياً عن الملكون الرئيس العربي(67). }
$$

خروج موريتانيا من منطقة النطاق (الفرنك الفرني) ثخ انضامها إلى الجامعة العربية، ثم إنشائها لعملتها الخاصة ذات الهسم العربي. توثيق العلاقة مع العراق الذي كان يسعى إلى تحويل موريتانيا إلى قاعدة استراتيجية عربية (عسكرية وسياسية) في المغرب العربي ضمن مساعي العراقي للتحكى في القرار السياسي الموريتاني.

قيام ضباط الزنوج بانقلاب عسكري فاشل في مورينانيا بدع مبانشر من السنغال وفرنسا عام 1987.
- مصر: بككم موققها المبدئي ووزنها الوقليمي ومبادئ الام المتحدة وحركة عدم الانياز ومنظمة المؤتمر الاسلاي، وقرارات منظمة الوحدة الافريقية التي تعترف

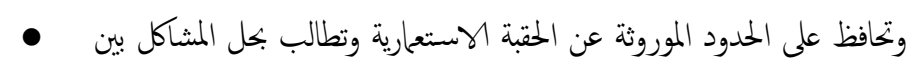
الدول الافريقية بالطرق السلمية واكدت على شرعية تشاد ومساندتها للحفاظ على سيادتها على ترابها الوطني من منطلق الحفاظ على الامن القومي- التشادي

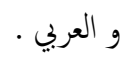
العراق: كان بكى الموقف اللببي المؤيد لايران في حرب الخليج الاولى ( 1980 1988 ) وترجمة ليبيا هذا الموقف بوضوح في تقديم السلاح والذخيرة والمساعدات المالية لايران في حربها ضد العراق ، قام العراق بدع تشاد بالسلاح و الذخيرة و العتاد و اقامة علاقات متميزة مع تشاد ومع معارضتها - لايياد حل توفيتي للمصالحة الوطنية بعد الحرب الاهلية و اكدت على شرعية النظام الحاكي في انجامينا و دع الرئيس (حسين حبري) ، وكذلك قام العراق بدعز المعارضة الليبية على الاراضي التشادية بالمال والسلاح والقدرات لتقويض نظام القذافي رداً على موقفها المؤيد لايران وهذا هو قدر الشعوب العربية من الانظمة الاستبدادية .

\subsection{8 المطلب الثالث: التحدي السنغالي}

النزاع الذي حدث بين موريتانيا والسنغال في عام 1992 وهو النزاع الذي يمتد الى عام 1982 وتجتم اللجنة المشتركة بين البلدين بين حين واخر لبحث مشاكل رعايا الدولتين ومنها حصر الاراضي الزراعية المستغلة من قبل رعايا الدولتين على ضفتي نهر السنغال بعد اندلاع النزاع الحدودي، حدثت تسوية وتم تعويض المتضررين من الطرفين وتم تحديد الاطار القانوني المناسب للمحافظة على حقوق المستغلين من رعايا الدولتين وحصة كل دولة من عدد الماثشية وحق المراعى في اراضي الدولة الاخرى (62). بدأت هذا التحدي من جديد عام 1989 كنزاع حدودي بين البلدين ثم تطورت إلى ازمة ثم إلى الحرب واستمرت لغاية 1991 في بداية النزاع الخلاف كانت على حدود نهر السنغال وكانت النتيجة هي اتفاق سلمي بتقسيم النهر بين الدولتين واسفرت هذا الحرب عن مقتل 1000 شخص من الطرفين(63) ومرت العنف بين الدولينين بمرحلتين، وها:المرحلة الاولى: امتدت الموجة الاولى من 22/ حتى 26 ابريل/ 1989 في السنغال على شكل فنتة شعبية عارمة في اقليم النهر ومنطقة داكار وكافة مدن وقرى السنغال وعلى نطاق اوسع في منطقة العاصمة ومدينة تيس في عام 1988 
O مجود مجموعات ضغط بين البلدين تراعي كل دولة المجموعة التي تضغط على

$$
\text { حكومة الطرف الاخر (71). }
$$

9. الخاتمة

يعد الوطن العربي من اكثر مناطق العالم احتككا بالعالم الخارجي وتاثرا بالعوامل الخارجية وتعليل ذلك الموقع الجغرافي الذي يتوسط العالم ـ ويربط القارات الثلاث بريا وهي قارة اوروبا ، اسيا ، افريقيا ، ويتحكم في اهم خطوط نقل ومواصلاته ـ ويمر كذلك طريق

$$
\text { الحرير القديم عبر المشرق العربي. }
$$

قامت الاطراف الوقليمة بمعاونة القوى العظمى بسلخ مساحات واسعة من اليابس

$$
\text { العربي وتقع حالياً خارج اراضي الوطن العربي . }
$$

اقليم الاهواز ، عربستان - ضمتها ايران الى اراضيها والاقليم متنازع عليه بين

$$
\text { العراق وايران مساحته } 165000 \text { كيلو متزمربع · }
$$

لواء الاسكندرونة ومساحته 40805 كيلومتر مربع التي ضمها تريكا بماونة فرنسا

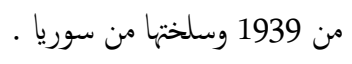

اقليم اوزو ومساحته 14000 كيلومتر مربع ضمنه تشاد الى اراضيها . اقليم جولاند تم اقتطاعها من اراضي الصومال من قبل بريطانيا ومنحته الى كينيا

$$
\text { في } 1924 \text {. }
$$

اقليم اوكادين الصومال تم احتلاله من قبل اثيوبيا في عام 1955 ـ. مدينة سبتة وملليلة المغربيتان اللتان تررحان تحت سيطرة اسبانيا . جزر ابو موسى و طنب الكبرى وطنب الصغرى الاماراتية التي تقع عند مدخل مضيق هرمز احتلنها ايران 1970 . فلسطين المحتلة من قبل اسرائيل 1948 .

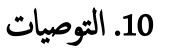
أ- الدول العربية بحاجة الى الارادة السياسية الحرة المستقلة . ب- تفعيل دور الجامعة العربية ومعاهدة الدفاع العربي المشترك. ت- تشكيل قوة عربية مشتركة لردع الدول الوتلمية من التدخل في شؤونها الداخلية
O حركة التعريب الذي قام بها موريتانيا عام 1976 وبدع من الحكومة العراقية. O مقت الدول الغربية وعلى رأسها فرنسا مع السنغال والذي لم تروقها هذه الاجراءات الموريتانية الاجرائية للنهوض(68).

O ت تأكيد شركة ((كوصموص) الاميركية وجود كميات هائلة من النفط والغاز في المياه التي تقع المى الحدود بين البلدين وماولة كل طرف فرض هيمنته على الاقليم المتنازع(69). O تحفظت السنغال على ترشيح الاتحاد الافريقي لموريتاينا كضو غير دائم في مجلس الامن في نهاية الثانينات من القرن الماضي . O ماول الرئيس السنغلي افشال المساعي الافريقية لحل الازمة الليبية في استهداف واضح لمشاعر الرئيس الموريتاني الذي ترأس ( لجنة الوساطة الافريقية) لحل الازمة الليبية.

O ان السنغال تحاول تصدير الازمة السياسية الداخلية إلى الخارج وهي محاولة الرئيس السنغالي إجراء تغييرات دستورية لها دالة التوريث لنجله كريم وادي وهو ما اصبح يطلق عليه في الصحافة السنغالية بالفضيحة الدستورية(70). O أما الحرك الخني الآخر - فهو تزايد مؤشرات الخلاف الموريتاني المغربي ويبري الحديث عنها مع كل تصعيد في ما يوصف بمحور الرباط- داككرباريس- ضد الحكومة المورينانية وسعيه لمضايقها في العديد من المجالات، وتصاعدت مؤشرات الخلاف بين مورينانيا- والمغرب أثر تعزية الرئيس الموريتاني لجهة البوليساريو، (المطالب بتأسيس دولة مستقلة) على الصحراء المغربية، عقب رحيل زعيمها محمد ولد عبدالعزيز وايفاده لوزير الشؤون الاسلامية لحضور تشيع جثمانه وكذلك ايفاد الحزب الحلك في موريتانيا لعضو المكتب التنفيذي للحزب ولد الزين لحضور المؤتمر الاستثنائي لجهية البوليساريو وهو المؤتر الذي انتخب الامين العام الجديد إبراهيم غالي وهي كلها خطوات استفزازية في نظر المغرب الحليف السنغلي الفرني إضافة إلى استضافة موريتانيا القمة العربية واعتذرت المغرب عن الحضور. 
11- عواطف عبدالرمن ، اسرائيل وافريقيا - 1948 - 1973 ، مركز الابحاث ، بيروت ، ، 1974

12- ر رشيد جبر الاسعد ، التغلغل الاسرائيلي في اريتيريا والحبشة ، دار القلم للنشر والتوزيع ، منشورات جهية التحرير الاريتيرية ، مكتب العراق ، بغداد ، 1970 .

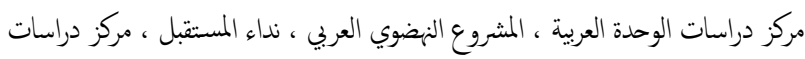
الوحدة العربية ، ط / 2 ، بيروت ، 2011 14- الجمهورية العربية الاسلامية الموريتانية ,الكتاب الابيض ,دار صنهاجة نواكثوط ,1989. 15- د.رشيد جبر الاسعد ,التغلغل الاسرائيلي في اريتيريا والحبشة دار القلم الشر و التوزيع منشورات جبهة التحرير الاريتيريه,مكتب العراق,بغداد,1970. 16- عواطف عبدالرمن ,اسرائيل و افريقيا 1948-1973,مركز الابحاث العربية ,بيروت,1974. 17- مركز دراسات الوحدة العربية المشروع النضوي العربي ,نداء المستقبل ,مركز دراسات

$$
\text { الوحدة العربية,ط2, بيروت,2011,ص } 35 \text {. }
$$

\subsection{1}

1- ابراهيم علي كرو ، مبدا حق تقرير مصير الشعوب والاستقناء عليه كوردستان العراق

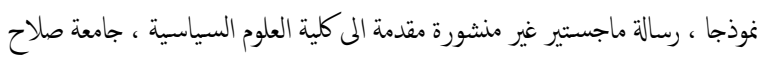

$$
\text { الدين ، اربيل ، } 2006
$$

2- عزالدين موسى صالخ عقيلة- النزاع الحدودي- اللبي التشادي 1973-195- رسالة ماجستير في العلوم السياسية غير منشورة مقدمة إلى كلية الاداب والعلوم، جامعة

$$
\text { الشرق الوسط- الاردن اب } 2006 .
$$

3.11 المجلات والدوريات

1- د. فؤاد خليل ، الشعوب العربية بين الاستبداد الداخلي والتدخل الخارجي ، مجلة الطربي ، العدد الثاني ، السنة 71 ، بيروت ، 2012

2- د. محدي صالح حمودي السامرائي ، الامن القوي العربي بين الواقع والطموح ، مجلة العلوم السياسية ، العدد / 3 ، بغداد ، 1998 ، ص 1.

\subsection{1}

1- مصر والسودان تخشيان خطر انهيار سد النضة الاثيوبي بعد 25 عاما ، جريدة ايلاف ، العدد / 4536 ، الثلاثاء 22 - 11 - 2013 ، متاح على الموقع : www.elaph.com/web/economics جريدة فاينانشال تايمز الصادرة يوم الاربعاء 13 - 11 - 2013 ، متاح www.vetogate.com : على الموقع
ث- انهاء الاغتراب بين السلطة والمجتع عن طريق التحول الى النظم السياسية

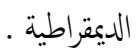

$$
\text { ج- ح- احترام منظومة الحقوق والحريات . }
$$

خ- التصدي لمظاهر العولمة الاقتصادية والثقافية والسياسية والاجتمعية . د- انهاء التبعية . ذ- منح الاقليات حقوقهم القومية والثقافية . ر- محاربة الفساد والفتر والبطالة.

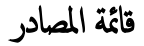

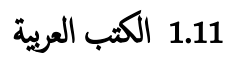

1- د. ابراهيم نافع واخرون ، نخو مشروع حضاري عربي ، ندوة الاهرام ، وكالة الاهرام للصحافة والنشر ، ط / 1 ، القاهرة ، 1994 . 2- د. جرجيس حسن ، تركيا في الاستراتيجية المريكية بعد سقوط الشاه ، ط 1/1 ، اورمية ،

1990

3- د. سعد الدين ايراهيم واخرون ، المجتع والدولة في الوطن العربي ، مركز دراسات الوحدة

$$
\text { العربية ، ط / } 3 \text { ، بيروت ، } 2005 .
$$

4- د. يوسف ابراهي الجهان ، تركيا واسرائيل ، دار حوران للطباعة والنشر ، ط / 1 ، دمشق بروس

1999 ،

5- د. علي صبيح ، النزاعات الوقليمة في نصف قرن 1945 - 1995 ، دار المنهل ، مكتبة راس النبع ، ط / 2 ، بيروت ، 2006 6- د. صبري فارس الهيتي ، الخليج العربي - دراسة الجغرافية السياسية ، دار الرشيد للنشر

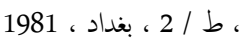
7- د. هيثم الكيلاني ، المشروع الحضاري العربي - والامن القوي من كتاب د. ابراهيم نافع

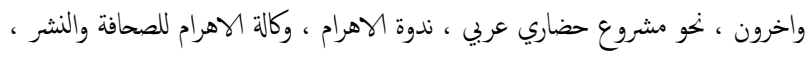

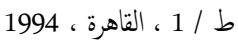
8- د. محمد سليم الزعنون ، سياسة الاتحاد الاوروبي تجاه الحرمات الاسلامية في المنطقة العربية ، دراسة حالة حركة المقاومة الهسلامية "حاس" - 2001 - 2007 ، مركز دراسات الوحدة العربية ، ط / 1 ، بيروت 9- د. عبدالفناح لطني عبداله , تحليل الابعاد الجغرافية لمشكلات الوطن العربي :الامن المائي روالامن الغذائي و. التحدي الليموغرافي ,وظاهرة التحضر. ط طع بعان,2015. 10- د. عصام مسن الجبوري ، العلاقات العربية الافريقية - 1961 - 1977 ، دار الرشيد

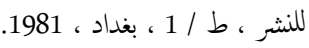




\section{صحيفة لوس انجلوس تايمز الصادر يوم الاربعاء 13-11-2013 متاح على الموقن www.eglovers,net\news \\ 8- مصر والسودان تخشيان خطر انهيار سد النهضة الاثيوبي بعد 25 عام ,جريدة ايلاف ,العدد 4536 ,الثلاثاء 22-11-2013,متاح على الموقع www.elaph.com/webleconomics}

5.11 1- فضائية العربية ، برنامج حول الملف النووي الايراني - العلاقات الايرانية الامريكية

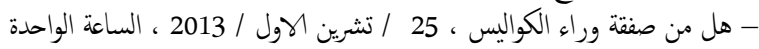
بعد الظهر

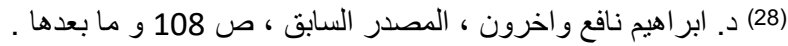

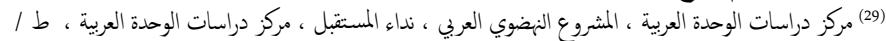

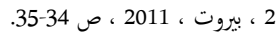

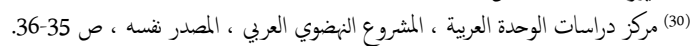

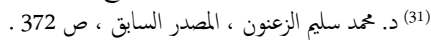

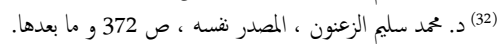

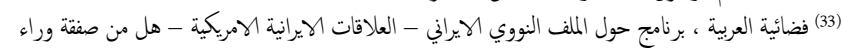

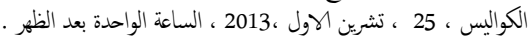

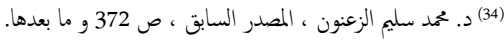

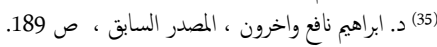

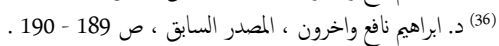

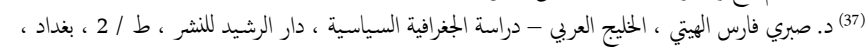

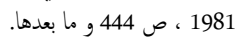

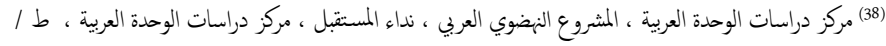

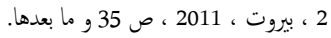

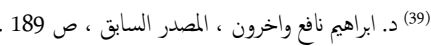

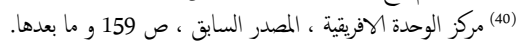

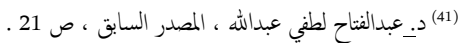
، 1921) د. عصام محسن الجبوري ، العلاقات العربية الافريقية - 1961 - 1961 - 1977 ، دار الرشيد للمنشر ، ط / 1 ، ، بغداد

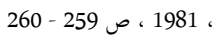
بعدها عواطف عبدالرمن ، اسرائيل وافريقيا - 1948 - 1973 ، مركز الابحاث ، بيروت ، 1974 ، ص 57 و ما

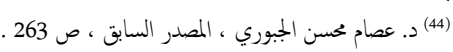

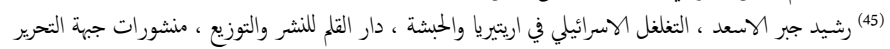

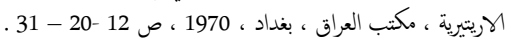

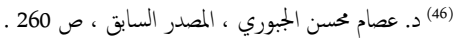

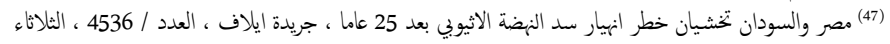

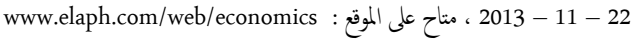

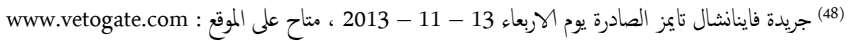

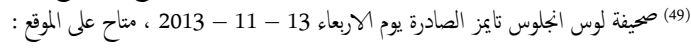
www.eglovers.net/news (50) صحيفة لوس انجلوس تايمز الصادرة يوم الاربعاء 13 - 11 - 2013 ، مثاح على الموقع : www.eglovers.net/news

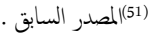

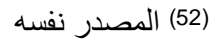
(53) د. ضياء الدين القوصي ، سد النيضة الاثيوبي ماذا بعد؟ ، جريدة الاهرام ، العدد / 46361 ، 4013 ، 17 - 11 -

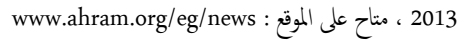

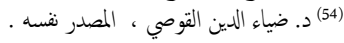

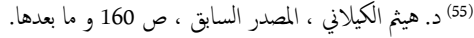

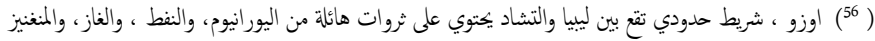

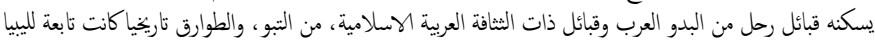

3- صحيفة لوس انجلوس تنايمز الصادرة يوم الاربعاء 13 - 11 - 2013 ،

www.eglovers.net/news : متاح على الموقع

4- دكتور محمد سالم موريتانيا و السنغال ,مسارات الازمة و تاريخ التعايش

www.rimafricinfo متاح على الموقع

5- هشام ولد مولاي ,النزاع السنغالي -الموريتاني .وكالة انباء اطلس متاح

على الموقع www.moqatel.com

ك-ضياء الدين القوصي ,سد النضة الاثيوبي ,ماذا بعد؟ جريدة الاهرام العدد

www.ahram.orgleg\news

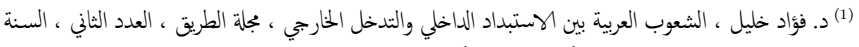

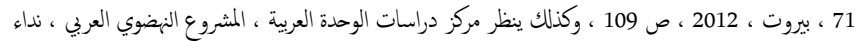

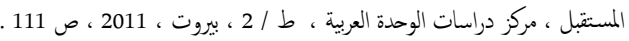

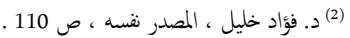

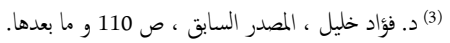

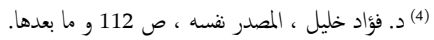

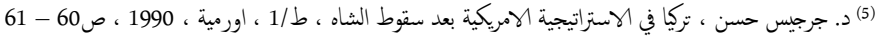

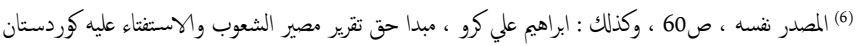

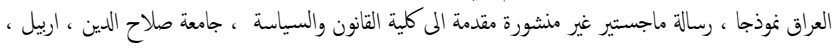

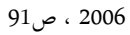
(7) د. يوسف ابراهيم الجهان ، تركيا واسرائيل ، دار حوران للطباعة والنشر ، ط / 1 ، دمشق ، 1999 ، ص 107 وما بعدها (8) المصدر نسه ، ص 95 - 95 - 103.

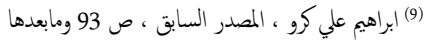

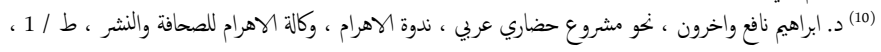

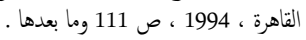

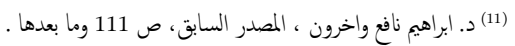

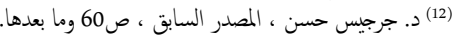

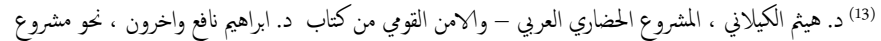

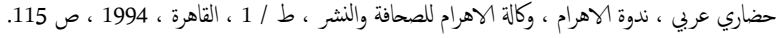

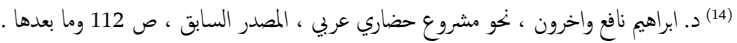

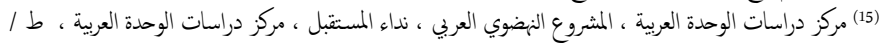

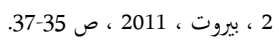

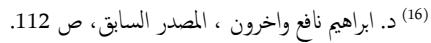

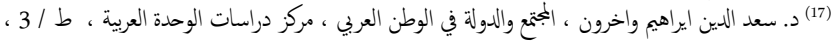

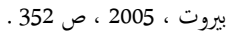
(18) د. علي صبح ، النزاعات الوقليمة في نصف قرن 1945 ، 1952 ، 1995 ، دار المنهل ، مكتبة راس النبع ، ط / 2 ، 2005

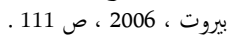

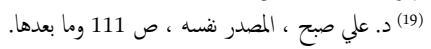

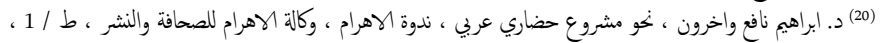

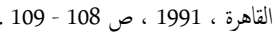

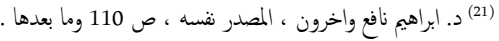

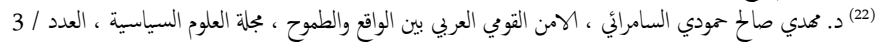

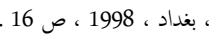

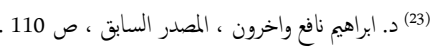

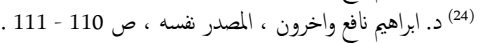

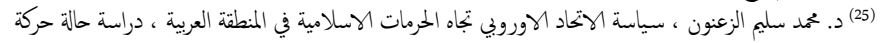

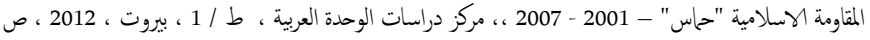
.376 (26) (26) المصدر السابق ، ص 376 و ما بعدها.

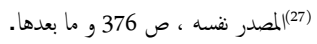




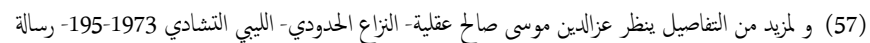

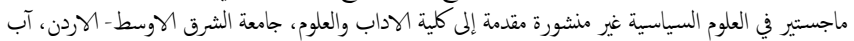

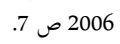

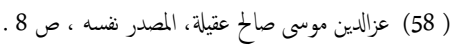

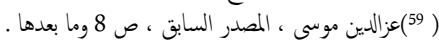

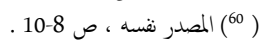

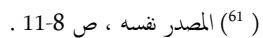

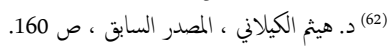

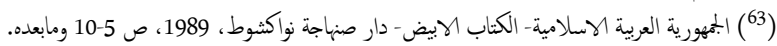

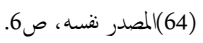

) (المصدر نتسه ص 65.7 (65)

(66) د.محمد سالم- موريتانيا- والسنغال ، وريم آفريك مسارات الازمة - وتأريخ التعايش متاح على الموق

www.rimafricinfo ) المصدر نفسه 67 (6) (68) د.محد سالم- موريتانيا- والسنغال مسارات الازمة- وتاريخ التعايش متاح على الموقع .www.rimafricinfo

) المجهورية العربية الاسلامية لموريثانيا، الكناب الابيض دار، صنهاجة، نواكثوط، 1989، ص 7)$^{69} .10$ anbaatlas.com هشام ولد مولاي- النزاع السنغلي- الموريتانية وكالة انباء أطلس متاح على الموقع (70) .www.moqatel.com $\left({ }^{71}\right)$ 